\title{
The concept and implementation of an energy retaining wall of large diameter piles
}

\author{
Octavian Bujor ${ }^{1 *}$, Iulia Prodan ${ }^{1}$, Augustin Popa $^{1}$ and Horia Ban $^{2}$ \\ ${ }^{1}$ Technical University of Cluj-Napoca, Faculty of Civil Engineering, 400114 Cluj-Napoca, Romania \\ ${ }^{2} \mathrm{SC}$ Termoline SRL, Department of Research, 410125 Oradea, Romania
}

\begin{abstract}
Performance and success of energy geostructures systems are already facts proven by research and practice. The number of implementations is in constant grow and due to their advantages, such systems have started to be implemented in a variety of structural elements. Among the various types, energy piles are the most common type of energy geostructures. However, most of the existing research, experimental sites and case studies refer to energy piles as a foundation element. This paper presents the concept and implementation steps of a different type of energy piles system which is a retaining wall of piles built in Cluj-Napoca, Romania. The paper is based on a real project case study, where large diameter piles are used as retaining wall for an urban excavation on a steep slope with high slope failure potential. The piles from the retaining system have been energy equipped in order to be used as an energy exchange element with the ground for heating and cooling demand of 3 new residential buildings from the same site. The paper will present the concept of an urban energy retaining wall and implementation stages of the project.
\end{abstract}

\section{Introduction}

Among the existing renewable energy resources (wind, solar, biomass, etc.), geothermal energy is one of the most complex renewable energy domains with various possible applications. In this context energy geostructures, as part of shallow geothermal energy systems, provide significant advantages that opens an exciting upcoming period for their implementation [1].

The innovative concept behind energy geostructures is to take advantage of the thermal capacity of the soil by using structural concrete elements of a building in connection with the soil and transport through them the renewable energy to the building for heating and cooling purposes. Soil surrounding the energy structure will become therefore the renewable energy source for heating and cooling of the buildings. The key factor that makes these systems operational refers to the constant ground temperature starting with approximate $6-8 \mathrm{~m}$ and up to $100 \mathrm{~m}$ depth $[2,3]$. This makes the soil an optimum energy exchanger and storage unit.

Statistics show that spread of energy geostructures is in constant growth in the new context of sustainable urban development and energy efficiency requirements. Energy systems have started to be implemented, not only in piles, but also in diaphragm walls and tunnels in various countries [4-7].

However, at a global scale, energy geostructures are a still relatively new technology, with smaller impact in comparison with other renewables. Eurostat statistics show also that in the residential sector, space heating and cooling consumes up to $65 \%$ of the total energy consumption. According to the same statistics, the main renewable sources used in energy consumption are biomass for heating and cooling, hydropower and wind for electricity, and biofuels for transport. Therefore, geothermal energy systems and especially energy geostructures seem to be underrated while their potential for impact within the frame of energy efficiency and low carbon footprint is significant. Even so, a larger spread for the energy geostructures could be achieved by a variety of measures such as: clear standardization, good practice guidelines, expanding of the existing knowledge on the systems also to other types of geostructures, additional monitoring data from in-place operational of real projects, etc.

This paper presents a new type of energy geostructures which is an energy pile retaining wall, as shown in Fig. 1. Retaining walls of energy piles system has a series of advantages related to its potential for implementation. Within the frame of a sustainable urban development, this type of energy geo-structure could be an excellent solution in ensuring energy efficiency or even energy independence of the new built buildings related to heating and cooling. Building in urban areas most often requires special retaining solutions to ensure the stability of the site and of the surrounding buildings. In addition, this type of geo-structure is very common in cities where development of new areas expands on the hilly terrains with slope instability potential. The new energy system has a series of challenges, as well that are different than in other known types of energy geostructures systems such as energy piles foundation or energy diaphragm walls. The main characteristics of the structure refer to the following: a. the structure itself is not part of the building for which will play as an energy generator, being situated at a certain distance from it, $b$. part of the structure will remain in permanent contact with the external

* Corresponding author: octavian.bujor@dst.utcluj.ro 
atmosphere after the excavation c. from the structural point of view, the stresses and strain distributions are different than in the case of energy piles foundations or energy diaphragm walls.

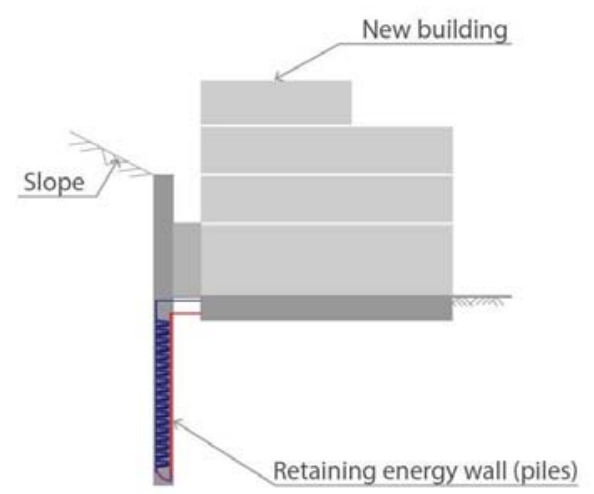

Fig. 1 Schematic representation of energy retaining wall of piles

\section{Description of the project}

In recent years, urban area of Cluj-Napoca, Romania started to expand with constructions onto the existing hills that surround the city. Due to slope stability problems, until approximately 10 years ago, the hill areas with high risk of slope stability around the city remained mostly untouched by constructions.

In terms of solutions for stability problems in urban areas, there are a few types of structures that could be used. Among these solutions, one is the pile retaining walls, which is one of the most frequently used. Since these structures are designed to sustain significant loads given by soil masses and existing surrounding buildings, they have usually important dimensions that require big quantities of concrete and steel.

The studied project is located on a slope, on the western part of Cetățuia Hill, an area where in the last century several slope failures occurred, some of them even with human deaths [8]. Three residential building of approximately 270 square meters footprint each, were designed to be constructed on the site as shown in Fig. 2.

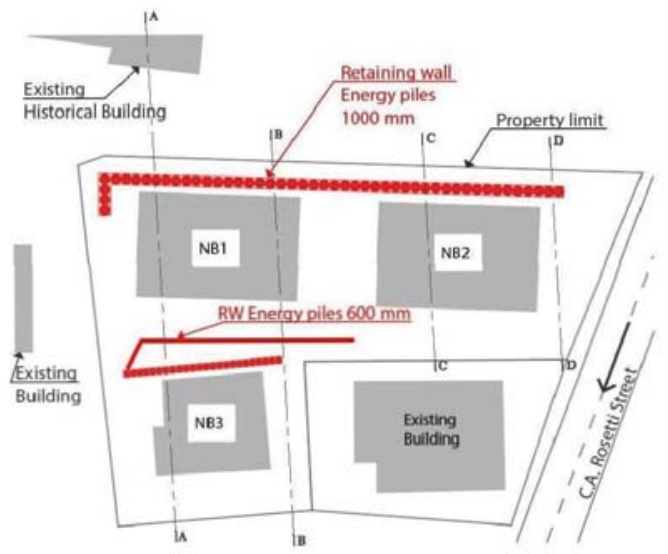

Fig. 2 Project site description
One of the challenges of the site is related to the presence of existing buildings and roads, surrounding it on the four sides of the property. In addition, the existing building on the uphill side is a Historical Building Residential House. The uphill house was built in the early 1920 s having a high susceptibility for deformation, requiring for the studied project special analysis of the top displacements regarding the retaining system in order to maintain the additional settlements at a minimum, during excavation steps.

In order to prevent any landslide events but at the same time to ensure the stability of the site and the surroundings, a retaining wall system was necessary to enhance the overall factor of safety of the slope. The slope inclination and necessary level of the excavation, required two retaining structures, one in the uphill of the site and another one between the buildings. For technological reasons in order to construct the new buildings, a 7.00 meters excavation in front of the uphill retaining wall was required.

\subsection{Geological, geotechnical and thermal description of the site}

The geotechnical report revealed two major lithologic units: a weathered colluvium deposit which consist of heterogeneous brownish silty clay and a Miocene age marine formation, with stiff/very stiff fissured clays, and decimeter thick volcanic tuff intercalations as a base layer.

Ground water is quartered inside the colluvium formation, and in the upper part of the stiff clay, where tuff/sand intercalations are present. For the geotechnical design of the retaining wall, and also for the evaluation of the safety factor of the slope, soil parameters showed in Table 1 were used in the design step.

Considering all these factors respectively the considerable thickness of soil deposits that are susceptible to slope failure, the depth of excavation needed and the presence of the historical building above the excavation, a rigid pile retaining wall resulted as a necessity in the uphill of the site, in order to maintain an equilibrium.

Table 1. Soil mechanical parameters

\begin{tabular}{|c|c|c|c|}
\hline Layer & $\begin{array}{c}\text { Effective } \\
\text { internal } \\
\text { friction angle } \\
{\left[{ }^{\circ}\right]}\end{array}$ & $\begin{array}{c}\text { Effective } \\
\text { cohesion } \\
{[\mathbf{k P a}]}\end{array}$ & $\begin{array}{c}\text { Deformation } \\
\text { modulus } \\
{[\mathbf{k P a}]}\end{array}$ \\
\hline Silty clay & 18 & 22 & 16300 \\
\hline Stiff clay & 22 & 38 & 21000 \\
\hline
\end{tabular}

For the thermal description of the site, laboratory methods, as well as correlations were used especially for the determination of the thermal conductivity. Thermal conductivity is one of the thermal parameters that show the geothermal potential of a site. It is well known that there are a number of factors that could have significant influence on thermal conductivity variations, such as water content and mineral composition [9]. Considering 
that on studied site the upper part of stratigraphy consisting of silty clay is a colluvium soil, it can be stated that the mineral composition is not a big influencing factor for the studied case. Guarded hot plate method has been used to determine thermal conductivity of type of soils encountered on the site with consideration of water variation influence. The results obtained showed values of thermal conductivity around $1.60 \mathrm{~W} / \mathrm{m} \cdot \mathrm{K}$, for the in-situ water content regarding the silty clayey soil. In the absence of a TRT equipment at the design step of the project and taking into consideration the possible error given by laboratory testing, a correlation was also used in establishing the thermal conductivity values needed for the energy design step. Therefore, Kersten formula (Eq. 1) for unfrozen loam and clay was used in order to have an order of comparison, [10].

$$
\lambda=[0.13 \cdot \log w-0.0288] \cdot 10^{0.000624 \rho_{d}}
$$

Considering average natural water content $[\%]$ and determined dry unit density $\left[\mathrm{kg} / \mathrm{m}^{3}\right]$, values of 1.43 $\mathrm{W} / \mathrm{m} \cdot \mathrm{K}$ were obtained for the upper part of the soil profile (silty clay) and a value of $1.78 \mathrm{~W} / \mathrm{m} \cdot \mathrm{K}$ for the lower stiff clay. These values show small variations between the values obtained in the laboratory, thus values estimated with Kersten formula were considered as acceptable in the design.

\subsection{Mechanical design consideration}

For the mechanical design and slope stability analysis 4 cross sections were used as shown in Fig. 2 (A-D). Of the 4 sections, cross-section A-A was considered the most critical due to the presence of the historical building on top of the site. A cropped schematic section of crosssection A-A, with proposed buildings figured, is presented in Fig. 3.

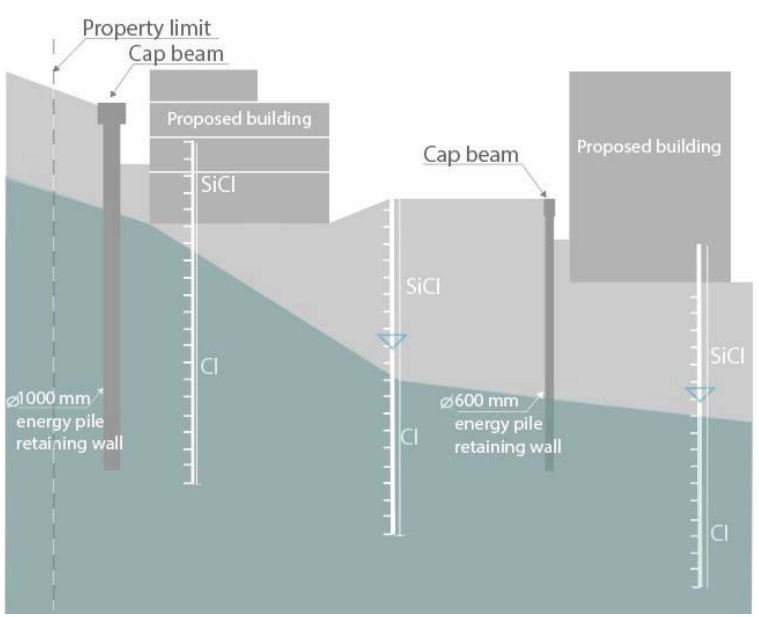

Fig. 3 Schematic section of the energy retaining wall system of piles

2D FEM calculations were used with consideration of the mechanical parameters shown in Table 1. Ground water level and variations throughout the year were also considered, with the highest level as a fixed level boundary condition imposed in design and considered at $3 \mathrm{~m}$ depth, behind the uphill pile retaining wall. The FEM analysis took into consideration several cross sections for capturing the relevant situations related to the overall stability of the site in all stages of the construction. Fig. 4 shows some of the construction stages in the cross section containing the NB1 and NB3 buildings with consideration of the historical building situated on top of the site. The results from the calculation for the energy retaining wall situated uphill, shown the necessity of a minimum diameter of $1000 \mathrm{~mm}$ for the piles with a length of the $21.5 \mathrm{~m}$ long. In the case of the retaining wall between the buildings resulted required diameter is of $600 \mathrm{~mm}$ with a length of piles of $13.5 \mathrm{~m}$. A specific distance of $10 \mathrm{~cm}$ was imposed between the piles in order to allow dissipation of pore water pressure and decrease the lateral load on the retaining system. The results of the FEM analysis were influenced by the restrictions regarding the imposed maximum accepted settlement of the historical building with respect to the most unfavorable construction stage represented by the excavation stage at $7 \mathrm{~m}$ measured from the top of the uphill retaining system. In this configuration, the maximum settlement for the historical house was limited to $2 \mathrm{~mm}$ and derived from the lateral displacement of the retaining wall in the final excavation stage.

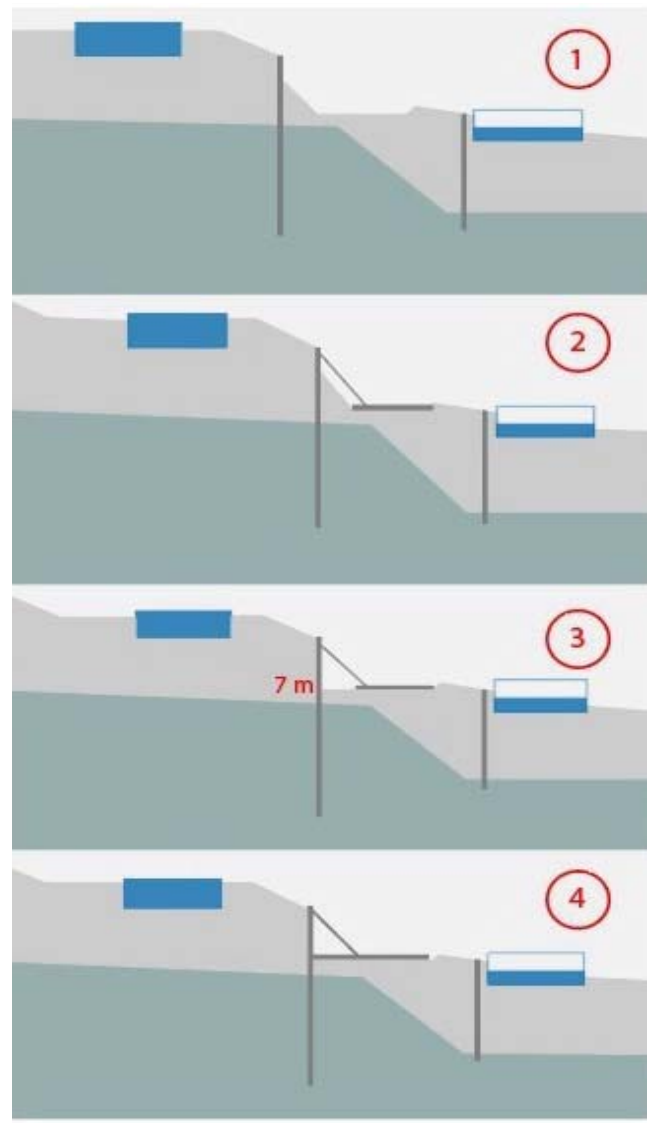

Fig. 4 Construction stages considered in the 2D FEM analysis

At an intermediate stage of the excavation a strut system for additional support, was considered. At the final step of excavation, resulted deflection in the design is of 
$10 \mathrm{~mm}$ at the top of pile retaining wall and of $18 \mathrm{~mm}$ at half distance between the raft foundation the strut system. The strut system was imposed to be maintained until the construction of the raft foundation and first level of the building is finished. The raft foundation was designed to ensure an additional support point for the retaining system.

\subsection{Energy considerations}

On the energy side, the design of the three buildings proposed, started from the concept of achieving the performance of Nearly Zero Energy Buildings. Therefore, considering the size of the retaining system, energy equipping of the piles was considered an excellent opportunity as main source for covering heating and cooling demands. Heating and cooling demands where designed according to SR 1907-1:2004 norm, from which resulted for each building a total heating demand of 32 $\mathrm{MWh} /$ year and a total cooling demand of $16 \mathrm{MWh} /$ year, domestic water demand being included in these needs. In order to ensure the demands, for each building a 14-kW heat pump resulted from the heat pump design stage. For the designed maximum water outlet temperature of the secondary system, of $35^{\circ} \mathrm{C}$, the power of heat pump is considered to be $14 \mathrm{~kW}$ at $0{ }^{\circ} \mathrm{C}$ heat source inlet temperature (primary circuit) and can increase to $18 \mathrm{~kW}$ for $10^{\circ} \mathrm{C}$ of inlet temperature.

The type of the energy geo-structure used, imposed certain limitations for the energy pipe installation from multiple points of view such as: placement of the technical room, air traps in the system, imposed execution steps and the fact that part of the uphill retaining wall will remain in permanent contact with the exterior. Considering all mentioned technical aspects, the system was designed to have the same elevation for the inlet/outlet of the primary circuit connections at the pile face for both retaining walls. Therefore, the equipped length for energy transfer with the ground is of $13.5 \mathrm{~m}$ from $21.5 \mathrm{~m}$ in the case of $1000 \mathrm{~mm}$ piles and of $12.5 \mathrm{~m}$ from $13.5 \mathrm{~m}$ for the $600 \mathrm{~mm}$ piles. Regarding the pipe configurations, in order to take advantage of the maximum energy potential of the buildings, each energy pile was equipped with spiral configuration, considered to be one of the most effective ways to equip an energy pile, Fig. $5[5,11,12]$.

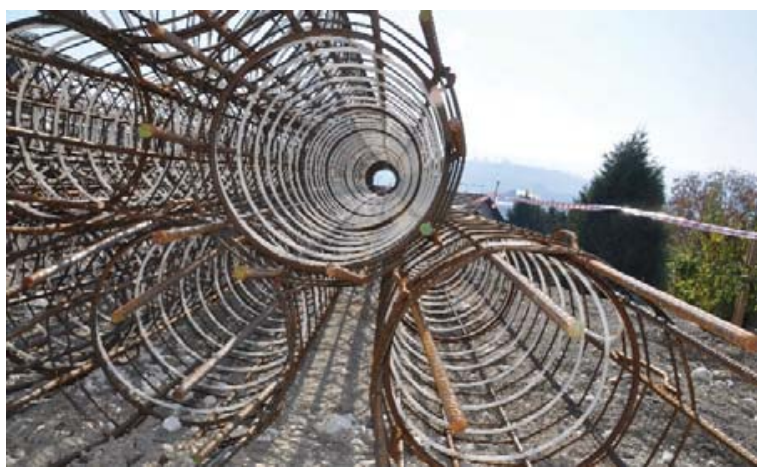

Fig. 5 Spiral shape pipes configuration installed in the $1000 \mathrm{~mm}$ piles
Compared to traditional pipe configuration, U, Double-U, high rates of transfer can be achieved per unit pipe[13]. The total length of equipped piles is of $730 \mathrm{~m}$ for the large diameter piles of $1000 \mathrm{~mm}$ and $337 \mathrm{~m}$ for the $600 \mathrm{~mm}$ diameter energy piles. Because spiral configuration was used to the detriment of regular configurations, the total length of the pipes used is significant higher.

Diameter of the pipes used for the primary circuit is of $16 \mathrm{~mm}$ with $2 \mathrm{~mm}$ wall thickness and made of PE-Xa material. The thermal conductivity of the pipes is 0.35 $\mathrm{W} / \mathrm{m} \cdot \mathrm{K}$, with a specific heat of $2.3 \mathrm{~kJ} / \mathrm{kg} \cdot \mathrm{K}$.

The secondary circuit of the entire heat pump system is represented by T.A.B.S system. In this case, for the structure of the buildings, the pipes are connected directly to the steel cages of the concrete slabs.

\section{Implementation stage}

Since the space on site was very restrictive, as can be observed in Fig. 6 and therefore with several technological limitations and constrains, a strict staging of execution was imposed. As a first stage, a gravel platform was constructed to raise the level of the site at the top level, platform imposed for the execution of the piles. Second stage was represented by the construction of the cap beam on top of the piles with the role of unifying the system. The following step was the excavation for the NB3 building, which started 14 days after pouring of the last $600 \mathrm{~mm}$ energy pile. After the first level of NB3 building was finished execution steps figured in Fig. 4 could be started.

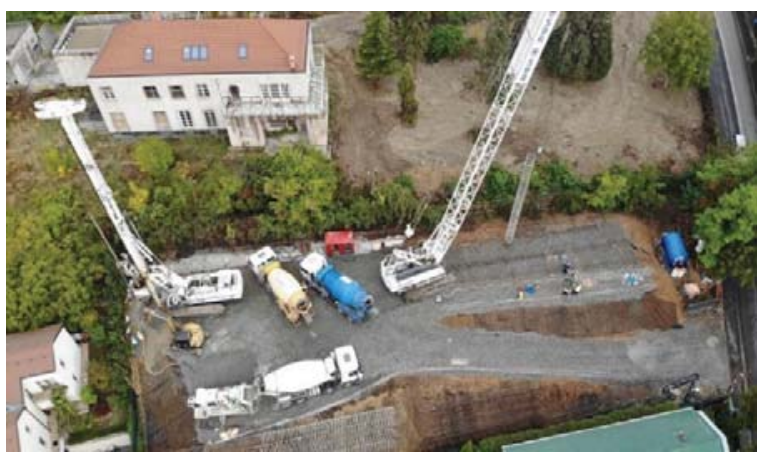

Fig. 6 Execution of the $1000 \mathrm{~mm}$ energy piles

The execution steps involved a series of supplementary measures that were meant to control the top displacement in the excavation stage, such as: stepped excavation, strut system, the use of building's raft foundation as a support for the pile energy wall through the struts, and a partial filling between the buildings and pile retaining wall. In case of $1000 \mathrm{~mm}$ pile retaining wall, the final depth in front of the wall will be of $3.5 \mathrm{~m}$.

Since the pipes where completely embedded into concrete, their further connections to the heat pump were planned to be made only after the final excavation part. Pressure tests on the pipes circuits were performed at this stage and for this specific project, given the control measures imposed during all steps of construction, the 
success rate for the integrity of the pipes was of approximately $95 \%$. In Fig. 7 can be observed the inlet and outlet pipes from each pile at the stage of extraction from the piles. For the primary circuit a number of 4 by 4 piles where connected together until the manifold from inside the technical room.

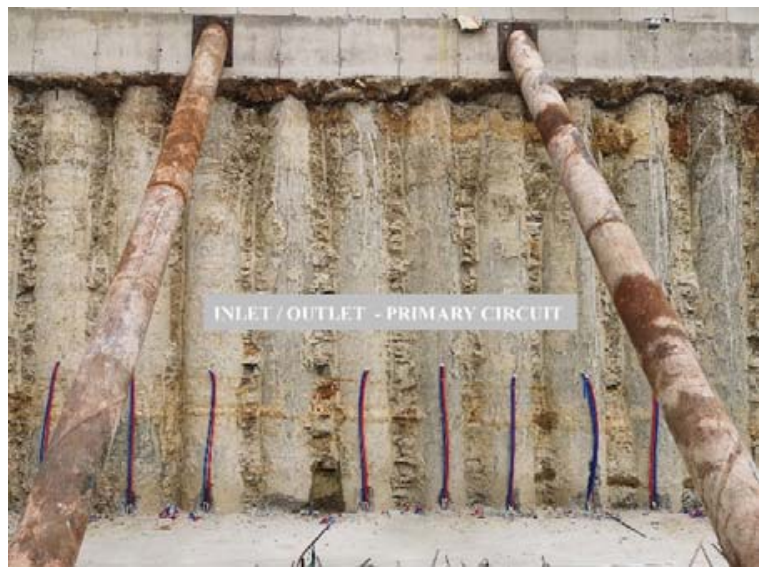

Fig. 7 Inlet and outlet of primary circuit at the bottom of excavation level at the extraction stage

\section{Final discussion}

\subsection{Identification of energy and thermo- mechanical challenges}

The energy geo-structure system represented by retaining wall of energy piles is a system that raises several questions and challenges in terms of both energy and thermo-mechanical behavior [14]. When relating to energy walls, the limited experimental data and especially numerical results show that when temperature variations occur, the behavior of energy walls is subjected to high changes in strains due to high rates at which heat transfer and dissipation of the pore water takes place [15]. However, the presented retaining wall of energy piles is expected to have differences in the thermo-mechanical behavior given by different factors such as: the stress distribution, that is different than in the case of energy diaphragm walls, and the fact that the piles are partially energy equipped.
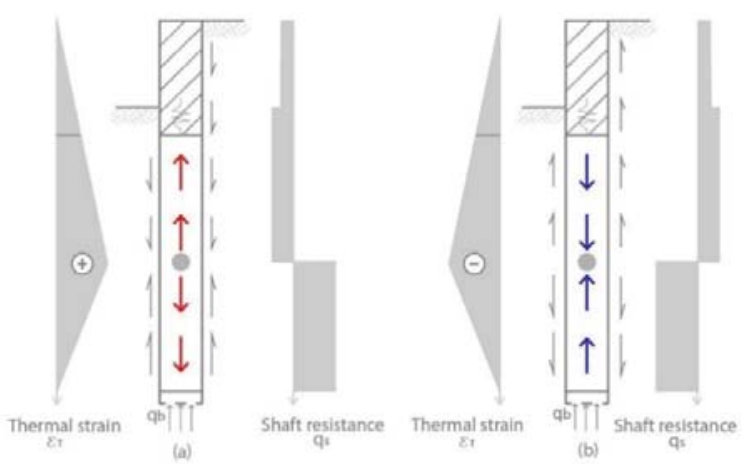

Fig. 8 Idealized expected thermal strains and shaft resistance during a) heating and b) cooling
In case of $1000 \mathrm{~mm}$ diameter energy piles considering the fact that from $21.5 \mathrm{~m}$ long energy pile, only the last $13.5 \mathrm{~m}$ are equipped with pipes in order to exchange heat with the ground, the thermal strains that occur inside the piles are different than common free-head energy piles, Fig. 8. The upper part of the energy pile that is not equipped, acts like a partial head restrained, owing to mobilization of shaft resistance. Since one face of the pile retaining wall will be exposed (due the excavation), on a final length of about $3.5 \mathrm{~m}$ (after partial filling), the shaft resistance during thermal loading will be reduced on this considered length.

The energy piles retaining system brings a series of challenges from the energy point of view also. On the technological side, the fact that the uphill retaining wall will remain only partially embedded in the soils, requires a special attention at the installation level of the energy system in the piles and also at its connection to the building, ensuring that a correct flow path for fluid in order to avoid air-trapping in the system, is being designed. In addition, for this specific case study, because of the pipes configuration and concept the energy capacity is affected as length of the $1000 \mathrm{~mm}$ piles is only partially used for energy transfer. In terms of energy behavior, since the distance between both $1000 \mathrm{~mm}$ and $600 \mathrm{~mm}$ diameter piles is relatively small, $100 \mathrm{~mm}$ respectively, could also negatively impact the energy performance of such systems because of temperature field intersection. However, the energy performance can also be optimized and enhanced after implementation of the project by a variety of measures such as: type of passing fluid, flux of the fluid, etc. Regarding this issue, in order to increase the precision of the model and establish more accurate parameters regarding thermal properties of the soils [16], Thermal Response Tests and Thermal Performance Tests were planned to be performed on the site, together with sensors measurements at different levels inside the pile.

The thermally induced stresses are dependent of a series of constraints of the retaining wall [17], thus when measured data is interpreted, a correct evaluation of the constraints must be done. Considering the large diameter of the piles, it is necessary to determine when concrete curing of the piles ended. Starting the system without fully cured piles, can make the interpretation of the strain data very difficult [18].

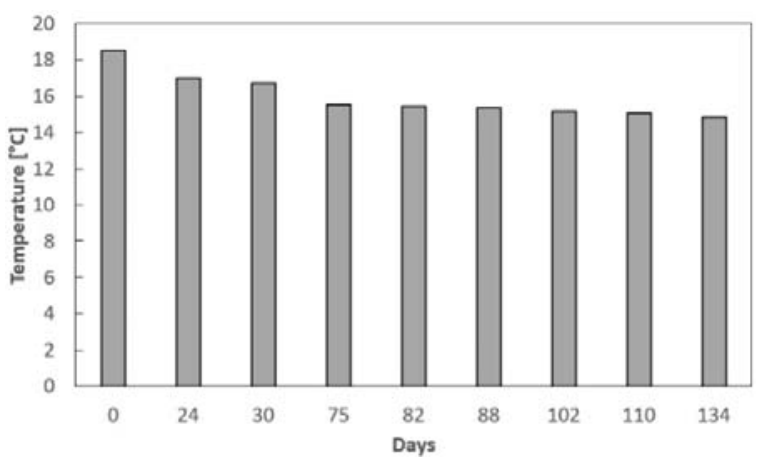

Fig. 9 Temperature evolution inside the pile

Regarding the monitored temperature inside the pile, a decrease of temperature of about $0.37^{\circ} \mathrm{C} / 10$ days for the 
first 75 days, followed by a decrease of $0.11^{\circ} \mathrm{C} / 10$ days for the following period can be observed, as shown in Fig. 9. The measured level is at a depth of $20 \mathrm{~m}$. In chart Day " 0 " is the reference reading for the current chart, done 40 days after the pouring of the piles, days following being the dates when readings were made.

\subsection{Monitoring}

State of the art shows that the existing research and applications of energy geostructures refer mostly to structural elements that are part of the building. There is a lack of data regarding research and in-place monitoring of energy piles as part of a retaining system despite their potential for large scale application in urban areas. In order to have a better understanding of the energy and thermo-mechanical behavior of such systems, a monitoring system was implemented in this project. The $1000 \mathrm{~mm}$ diameter piles were equipped with vibrating wires strain gauges sensors (Fig. 10), NTC temperature sensors, MEMS and inclinometers. Vibrating wire sensors were chosen for their reliability and stability for long-term measurements of strain and temperature inside the structural element, being placed at different levels. The thermistors, NTC sensors are attached to the PE-Xa pipes embedded in concrete, in order to monitor the temperature inside the pipe at different levels [19]. In order to address to another challenge, that of analyzing the horizontal deformation variation of the pile wall during heating, MEMS (uniaxial tilt) and inclinometer were also installed.

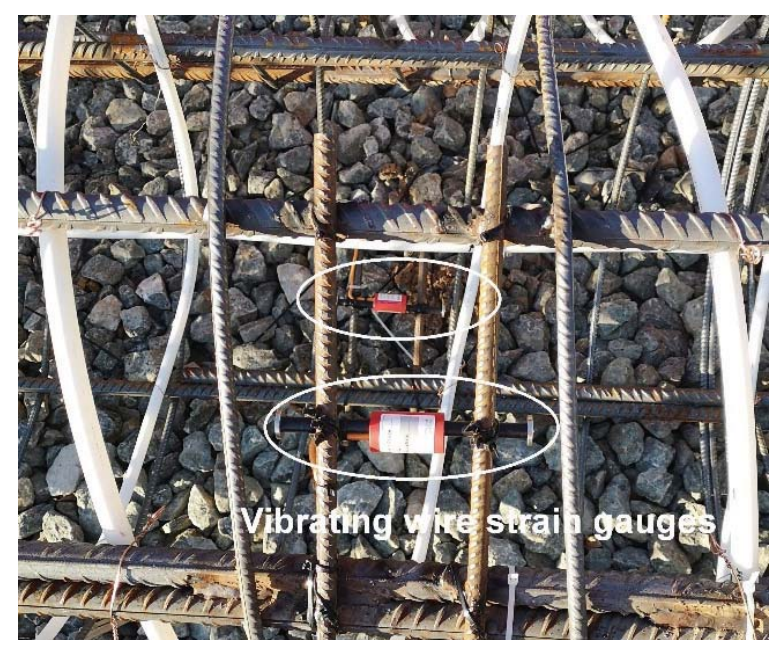

Fig. 10 A section from energy pile with installed vibrating wire sensors

\subsection{Conclusion}

The current project represents a pioneering project in the field of pile retaining walls, based on its concept. It is a type of retaining system that is very common in urban areas and thus energy activation of this type of structures (i.e. pile retaining wall) could provide important contribution to $\mathrm{CO}_{2}$ emissions reductions in urban environments. It is a sustainable and cost-effective solution that ensures the exploitation of a local renewable energy source. The energy pile retaining wall is an excellent solution for addressing two current challenges of the construction sector in developing cities: a. providing suitable solutions for the stability issues of urban excavations and $b$. finding easy to implement and sustainable renewable energy solutions for greener cities.

However, despite their clear advantages, additional research is required in order to fully understand the behavior of such systems from both energy and thermomechanical perspectives.

\section{References}

1. L. Laloui and M. Sutman, Proceedings of the XVII ECSMGE-2019 5173 (2019)

2. A. Manzella, EPJ Web of Conferences 22 (2014)

3. M. de Moel, P. M. Bach, A. Bouazza, R. M. Singh, and J. O. Sun, Renewable and Sustainable Energy Reviews 14, 2683 (2010)

4. A. Di Donna, M. Barla, and T. Amis, in Proceedings of the 42nd Annual Conference on Deep Foundations (LA, USA, 2017), p. 11

5. F. Loveridge, J. S. McCartney, G. A. Narsilio, and M. Sanchez, Geomechanics for Energy and the Environment 22, 100173 (2020)

6. D. Nicholson, P. Smith, G. A. Bowers, F. Cuceoglu, C. G. Olgun, J. S. McCartney, K. Henry, L. L. Meyer, and F. A. Loveridge, DFI Journal - The Journal of the Deep Foundations Institute 8, 130 (2014)

7. C. Xia, M. Sun, G. Zhang, S. Xiao, and Y. Zou, Energy and Buildings 52, 50 (2012)

8. F. Wanek and S. Poszet, Acta Pericemonologica 83 (2008)

9. N. H. Abu-Hamdeh and R. C. Reeder, Soil Sci. Soc. Am. J. 64, 1285 (2000)

10. M. S. Kersten, Thermal Properties of Soils, University of Minnesota, 1949

11. A. Zarrella, M. De Carli, and A. Galgaro, Applied Thermal Engineering 61, 301 (2013)

12. Y. Cui, J. Zhu, S. Twaha, and S. Riffat, Renewable and Sustainable Energy Reviews 94, 84 (2018)

13. Q. Zhao, B. Chen, M. Tian, and F. Liu, Energy 162, 787 (2018)

14. N. Makasis, G. A. Narsilio, A. Bidarmaghz, I. W. Johnston, and Y. Zhong, Computers and Geotechnics 120, 103399 (2020)

15. E. Sailer, D. M. G. Taborda, L. Zdravković, and D. M. Potts, Computers and Geotechnics 109, 189 (2019)

16. L. Jensen-Page, F. Loveridge, and G. A. Narsilio, Energies 12, 2700 (2019)

17. D. Sterpi, A. Coletto, and L. Mauri, Geomechanics for Energy and the Environment 9, 1 (2017)

18. B. H. Fellenius, Geotechnical News Magazine 20, $35(2002)$

19. R. Nie, W. Leng, Q. Yang, and Y. Frank Chen, Soil Mech Found Eng 55, 76 (2018) 